Jokes in the Store and its Effects on Customer Satisfaction

Magnus Söderlund ${ }^{1}$, Eeva-Liisa Oikarinen ${ }^{2}$ and Eija-Liisa Heikka ${ }^{2}$

${ }^{1}$ Corresponding author: Stockholm School of Economics, P.O. Box 6501, SE-113 83, Stockholm, Sweden, Magnus.Soderlund@hhs.se, telephone: +46-8-736 9541.

${ }^{2}$ Oulu Business School, University of Oulu, Oulu, Finland 


\title{
Jokes in the Store and its Effects on Customer Satisfaction
}

\begin{abstract}
:
This study assesses the impact of employee use of jokes embedded in face-to-face conversations with customers. Our main finding - derived from experiments in which employee use of jokes was manipulated - was that jokes reduced customer satisfaction. This reduction occurred regardless if jokes was related or unrelated to the employee's overall message. Our results also indicate that the use of jokes had a negative impact on perceived message relevance, and that perceived relevance mediated the link between employee use of jokes and customer satisfaction. In addition, our results show that no joke usage versus joke usage did not produce different emotional responses. This suggests that the impact of jokes on affect is attenuated when jokes are embedded in conversational content.
\end{abstract}

Keywords: Humor, jokes, customer satisfaction, perceived relevance, service encounters 


\section{Introduction}

Extensive previous research shows that many characteristics and behaviors of employees in face-to-face encounters with customers influence customers' overall evaluations such as customer satisfaction (e.g., Bitner, Booms, and Tetreault 1990). So far, however, employees' use of humor in such encounters has received limited attention. Some authors have observed that humor is sometimes used by employees in their interactions with customers (Gilliam, Flaherty, and Rayburn 2014; Gwinner, Gremler, and Bitner 1998; Locke 1996; Pearce 2009; Price, Arnould, and Tierney 1995; Ryoo 2005), but very little is known about the effects of humor usage in a commercial face-to-face setting (Mathies, Chiew, and Kleinaltenkamp 2016).

The effects of humor in a marketing context, however, have been examined in several studies dealing with advertising. A main pattern emerging from such studies is that humor in an ad can boost customers' evaluations of both the ad itself (Duncan 1979; Eisend 2009; Madden and Weinberger 1984; Weinberger and Gulas 1992) and the advertiser (Eisend 2009; Sternhal and Craig 1973; Weinberger and Gulas 1992). Other positive advertising effects of humor have also been suggested, such as that humor may increase memorability and overcome resistance (Scott, Klein, and Bryant 1990).

Given that both employee behavior in a face-to-face encounter and ads serve to communicate with customers, it may be expected that humor would have a positive impact on customer satisfaction when it is used by employees in their face-to-face interactions with customers. However, humor-comprising communications in ads and face-to-face encounters are different, because most ads with humor have little other content than humor per se (Spotts, Weinberger, and Parsons 1997). In contrast, when humor is used by an employee in a face-to-face encounter, humor is typically embedded in conversation content comprising also other elements. Indeed, this is the way in which humor typically appears also in everyday use (Norrick 1994). This aspect, we assume, produces different conditions for the customer's information processing activities. More specifically, in a face-to-face setting, we assume that humor usage in terms of joke-telling can attenuate the customer's comprehension of other message content, so that the result is a reduction in perceived message relevance. And given 
that perceived relevance is likely to be positively associated with customer satisfaction, we expect that employees' use of joke-telling has negative effects on customer satisfaction.

Our purpose here is to assess these assumptions. More specifically, we examine the effects of employee use of jokes in conversations with customers - in a face-to-face setting - on customer satisfaction, and we explicitly assess the role of perceived relevance as a mediating variable. The reasons behind our focus on customer satisfaction as an outcome variable are that it has a dominant position in many marketing theories, it is used frequently as a goal variable in managerial practice, and it has been shown to positively affect many firm performance-related variables (Luo and Homburg 2007). Given that humor is often assumed to create positive emotional reactions (Lyttle 2001; Nabi, Moyer-Gusé, and Byrne 2007), which in turn has implications for various information processing activities (van Dolen, de Ruyter, and Streukens 2008; Forgas 1995; Forgas and George 2001), we also examined the potential for employee use of jokes to influence emotions. Three experiments were employed to test the assumptions.

\section{Theoretical framework and hypotheses}

\section{Humor and jokes}

According to existing humor typologies, there are many types of humor (Speck 1991; Spotts et al. 1997; Weinberger and Spotts 1989). Yet the very core of the humor construct is typically a deviation from what is expected. In other words, incongruity is intimately related to humor (Alden and Hoyer 1993; Alden, Hoyer, and Lee 1993; Graham, Papa, and Brooks 1992; Krishnan and Chakravarti 2003; Lee and Mason 1999; Martin 2001; Morkes, Kernal, and Nass 1999; Norrick 2009; Robinson and Smith-Lovin 2001; Ruch, McGhee and Hehl 1990; Spotts et al. 1997). As already indicated, the use of humor in commercial face-to-face encounters has been documented in several studies (e.g., Gwinner et al. 1998; Locke 1996; Pearce 2009), but the impact of joke-telling on customers' reactions has rarely been assessed. Our main rationale for examining jokes - as one particular form of humor - is that joking can be seen as the prototypical form of verbal humor (Dynel 2009). 


\section{Humor and its effects in an advertising setting}

The main source of knowledge of the effects of humor in marketing settings is advertising studies. And a main pattern emerging from such studies is that humor in an ad can have a positive influence on attention to the ad (Duncan 1979; Eisend 2009; Madden and Weinberger 1984; Spotts et al. 1997; Weinberger and Gulas 1992), the attitude towards the ad (Eisend 2009; Weinberger and Gulas 1992), the attitude towards the advertiser (Eisend 2009; Sternhal and Craig 1973; Weinberger and Gulas 1992), and ad recall (Spotts et al., 1997). Such positive effects are particularly likely in a low involvement setting (Chung and Zhao 2003; Speck 1991); in this case, humor serves as a peripheral cue and thus not as a strong argument. In other words, the effectiveness of humor in ads is likely to be reduced in a high involvement setting in which strong arguments are expected (Fugate 1998; Nabi et al. 2007; Oikarinen and Söderlund 2016).

\section{Employee use of jokes in face-to-face-interactions with customers}

Given that both ads and employee behavior in a face-to-face encounter serve as communication means vis-à-vis customers, and given several positive effects of humor in an advertising setting, it is tempting to assume that jokes and other forms of humor would have a positive impact on customers' responses also when used by employees in conversations with customers. This assumption would be consonant with the idea that humor is universally adaptable to almost any medium (Fugate 1998). Indeed, some authors have suggested that humor in a face-to-face setting may reduce negative emotions, enhance perceptions of interaction partners (Locke 1996), positively impact rapport (Ryoo 2005), increase trust (Bergeron and Vachon 2008; Lyttle 2001), and provide the customer with social benefits (Gwinner et al., 1998).

However, the findings in previous advertising studies (indicating that humor in ads can have positive effects on consumers' evaluations) should be seen in the light of the fact that ads comprising humor typically have little other information content besides humor itself. Indeed, most ads with humor are 'humor dominant', in the sense that if the humorous elements are removed the ad no longer makes sense (Spotts et al. 1997). In contrast, a face-to-face encounter between an employee and a customer in a store or in a service setting contains 
exchange of information of various types; that is to say, when humor is used in such encounters, it is embedded in other conversation content (Pearce 2009; Ryoo 2005).

Some authors have noted that humor used in everyday conversations may disrupt conversations (Norrick 1994), and this is a main assumption in the present study. More specifically, in a setting with face-to-face exchange of information between the employee and the customer, and particularly when there is some level of complexity in the information exchange, we assume that the employee's use of humor can reduce perceived relevance from the customer's point of view. Relevance in a communication context is defined here as material pertaining directly to the meaning of the theme in a message, and it reflects how information elements contribute to or detract from a clear identification of the theme (Heckler and Childers 1992; Lee and Mason 1999). In other words, the more integrated all message elements are, the higher the message relevance (Ang, Lee, and Leong 2007). Empirical results indicating that humor can reduce perceived relevance are provided by Nabi et al. (2007), who found that perceived humor in a message was positively associated with message discounting (i.e., the message is dismissed as not containing information relevant to serious judgments).

One main reason why humor is likely to introduce irrelevance is that humor (by definition) involves incongruency - and, in general, incongruency demands cognitive effort from the receiver (Houston, Childers, and Heckler 1987; van Mulken, van Enschot, and Hoeken 2005; Sujan, Bettman, and Sujan 1986). Indeed, a common effect of exposure to humor is increased cognitive processing (van Dolen et al. 2008). Additional effort is required from the receiver when humor appears in the common form of jokes involving third parties (i.e., persons referred to in jokes), because this introduces the mindstates of others than the joke-teller and the listener - and there is a limit to how many such mindstates one can deal with before becoming overtaxed (Dunbar, Launay, and Curry 2016). It is therefore not surprising that humor may harm comprehension (Krishnan and Chakravarti 2003). Humor, then, can be seen as an irrelevant conversation element because of the cognitive effort it involves - and such effort is likely to interfere with the receiver's interpretation of the theme conveyed in a message (Krishnan and Chakravarti 2003). A similar argument has been raised by Cantor and Venus (1980), who claim that humor embedded in a message may draw attention to itself and distract attention from information being presented concurrently. 
The disruptive potential for humor in a face-to-face conversation should also be seen in the light of the real time aspect of this setting. That is to say, when humor appears as a part of a conversation, there are typically few opportunities for the receiver to stop the conversation in order to be able to reflect on the incongruence involved in humor, because an interpretation must be made fast - otherwise the receiver runs the risk of being perceived as someone with limited comprehension ability. Indeed, exposure to humor has been equated to being subject to 'a little intelligence test' (Norrick 1994). This aspect, we assume, adds to the cognitive challenges of the receiver of humor.

It should be noted that comprehension in a face-to-face context, in which two parties are engaged in social interaction, does not only call for attempts to make sense of humor per se (such as trying to understand a joke). Comprehension also comprises needs to understand why an interaction party uses humor in the first place. Indeed, humor usage in social interactions suspends the usual give-and-take of everyday talk (Norrick 1994). Humor usage in this context may involve bonding attempts (Boxer and Cortés-Condes 1997; Dunbar et al. 2016; Hay 2000; Martin, Puhlik-Doris, Larsen, Gray and Weir 2003), attempts to control or manipulate the receiver (Graham et al. 1992; Hay 2000; Martin et al. 2003; Norrick 2009), attempts to gain approval (Martin et al. 2003), and attempts to create status differentiation (Robinson and Smith-Lovin 2001). Humor may also be used to signal genetic quality for mating purposes (Cowan and Little 2013). Such aspects, we assume, encourage the receiver to make sense of humor usage (thus not only of humor per se) in such a way that attention to other parts of the conversation is compromised. In the light of this, and given that jokes are subject to similar effects as other types of humor, we hypothesize the following:

H1: Jokes used by the employee in face-to-face interactions with the customer reduces the customer's perceptions of relevance of the employee's message

Jokes, however, can be subject to variation in terms of its fit with the information package in which it is a part. In other words, the humor part of a message can be more or less related to the overall theme of the message or the offer (van Dolen et al. 2008; Erevelles 1998; Scott et al. 1990, Spotts et al. 1997). Here, we view variation in this sense in relevance terms. More specifically, given employee use of jokes in communications with a customer, we assume that the level of fit between used jokes and the offer would moderate the use of joke-perceived relevance association, so that jokes related to an offer produce a relatively lower reduction in 
perceived relevance compared to jokes not related to the offer. Thus the following is hypothesized:

H2: Offer-related jokes used by the employee in face-to-face interactions with the customer reduces the customer's perceptions of relevance of the employee's message less than use of jokes unrelated to the offer

In the next step of the customer's information processing activities, we expect that perceived relevance of a message influences the customer's overall evaluations of the message, a finding consistent with the results in Smith, Chen, and Yang (2008). In addition, prior research in an advertising setting has shown that relevance has a positive impact on evaluations of the ad and evaluations of the advertised brand (Lee and Mason 1999). This influence can take several routes. Relevance facilitates understanding of messages (Heckler and Childers 1992; Smith et al. 2008) and, in an advertising setting, understanding of ads has been shown to be positively associated with ad evaluations (Phillips 2000). Relevance is also likely to result in more upbeat feelings and less negative feelings (Ang, Lee, and Leong 2007) and a higher level of perceived entertainment value (Smith et al. 2008). In addition, a relevant message is likely to enhance processing fluency, which is can result in positive affect (Reber, Winkielman, and Schwarz 1998). Taken together, these outcomes suggest a positive association between message relevance and evaluations of a message.

Moreover, in a setting in which a message is transmitted to a customer by an employee on a face-to-face basis, we assume that message characteristics (such as perceived relevance) have a valence-congruent impact on the customer's overall evaluations. More specifically, we expect that the content of the employee's conversation with the customer is capable of influencing the customer's overall evaluations of the supplier for which the employee works (Webster and Sundaram, 2009). This is consonant with a common assumption in the service literature, namely that the employee $i$ s the firm from the customer's point of view (Bitner et al. 1990; Surprenant and Solomon 1987). It is also consonant with the notion that conversation is a key element in encounters between the employee and the customer (e.g., Grewal, Levy, and Marshall 2002; Haas and Kenning 2014). As for the specific overall evaluation of the firm in the present study, we focus on customer satisfaction; we view customer satisfaction as a global, post-choice evaluative judgment capable of summarizing the customer's overall impressions of an offer. 
Given that the employee's use of jokes would reduce perceived message relevancy (H1), then, and given that the characteristics of the employee's message to the customer in a face-to face setting has an impact on customer satisfaction, we assume that jokes used by an employee as one among several elements in the information exchange with a customer - would have a negative impact on customer satisfaction. The following is therefore hypothesized:

H3: Jokes used by the employee in face-to-face interactions with the customer reduces customer satisfaction

However, given that offer-related jokes are expected to produce a lower reduction in perceived relevance compared to jokes not related to the offer (Hypothesis 2), and given an impact of perceived relevance on customer satisfaction, we expect that offer-related jokes would produce a lower reduction in customer satisfaction than jokes unrelated to the offer. Indirect support for this has been provided by authors suggesting that humor is likely to produce positive effects when it is directly related to an overall message, while humor unrelated to the message has a potential to produce negative responses (van Dolen et al. 2008; Fugate 1998; Scott et al. 1990). In our case, then, we expect that the reduction in customer satisfaction following the employee's use of jokes (Hypothesis 3) would be lower when jokes are related to the offer compared to when they are unrelated to the offer. Thus the following is hypothesized:

H4: Offer-related jokes used by the employee in face-to-face interactions with the customer reduces customer satisfaction less than use of jokes unrelated to the offer

Three studies were employed to test the hypotheses. Study 1 tested H1-H4, Study 2 was carried out to examine if joke usage impacts also positive affect, and Study 3 retested $\mathrm{H} 1$ and $\mathrm{H} 3$ (and retested the potential for an emotional impact of joke usage). 


\section{Study 1}

A between-subjects experiment was conducted to assess H1-H4. The experimental design comprised a joke factor with three levels: (1) no joking, (2) jokes unrelated to the offer, and (3) jokes related to the offer. For the manipulations, we used a text-based role-play scenario approach involving an employee-customer encounter in a retail setting. Scenarios of this type have been used frequently in previous research (e.g., Bitner 1990; Karande, Magnini, and Tam 2007; Söderlund and Rosengren 2008), and one main advantage is that they allow for homogenous treatments within treatment groups (and control of other factors).

\section{Stimulus development}

The beginning of the scenario instructed the participants to assume the role of a customer who, on a very sunny day, was in an eyeglass store to purchase sunglasses. In this store, the customer interacted with an employee who informed the customer about various sunglasses aspects. It should be noted that one of our key conceptual constructs, relevance, is defined in terms of how various parts of a message are related to a theme (Heckler and Childers 1992; Lee and Mason 1999), and the specific message theme selected for the Study 1 scenario interaction was differences between cheap and expensive sunglasses.

Three version of the scenario were created for our manipulations. In the two joke conditions, the employee used two short jokes embedded in the conversation. For the offer-related joke condition, the manipulation comprised two jokes explicitly dealing with sunglasses; the offerunrelated joke condition comprised two jokes with no relation to sunglasses. The presence or absence of sunglasses in the jokes were thus assumed to represent different levels of relatedness to the theme. The third version contained no jokes. Everything else that happened in the scenarios was kept constant (see Appendix 1). The form of humor used in the manipulations were thus joke-telling embedded in a conversation (Boxer and Cortés-Conde 1997; Norrick 2003), and the specific jokes were all of the type that they involve third parties (Dunbar et al. 2016). In overall message terms, the messages used for the manipulations involving jokes can be seen as 'message dominant', in the sense that the jokes were subordinate to the overall message. That is to say, in this case the jokes can be removed with no loss in message comprehension (Spotts et al. 1997). 


\section{Participants and data collection}

The participants in the experiment $(n=97 ; 29$ men and 66 women, two participants declined to report gender; $M_{\text {age }}=26.32$ ), which we recruited from participants in business administration courses, were randomly allocated to one of three scenario versions. The main rationale for using a student sample can be found in, for example, Calder, Philips and Tybout (1981) and Katz (1972). After having read the scenario text, the participants were asked to respond to a set of questionnaire items.

\section{Measures}

Perceived relevance was measured as a response to a question about what the employee said to the customer in the store. Four adjective pairs were used: 'Few things were relevant-Many things were relevant', 'Weak connection to what I wanted to buy-Strong connection to what I wanted to buy', 'Low level of fit with the buying situation-High level of fit with the buying situation', and 'Certain parts of the content were not appropriate-Most parts of the content were appropriate. Similar items have been used by, for example, Ang et al. (2007), Krishnan and Chakravarti (2003), and Lee and Mason (1999). They were scored on a 10-point scale (a low score indicates a low level of perceived relevance). Cronbach's alpha for this scale was .91 , and we used the average response to the four items as a measure of perceived relevance. To assess the validity of this scale we used a single-item measure of how easy it was to understand the employee; it was scored on a scale ranging from 1 (difficult) to 10 (easy). The response to this item was positively and significantly associated with the response to the relevance scale $(r=.62, p<.01)$. Given the theoretical argument that relevance facilitates understanding of messages (Heckler and Childers 1992; Smith et al. 2008), our relevance measure thus behaved in an acceptable way from a nomological validity point of view.

To measure customer satisfaction, we used the three satisfaction items employed in many national satisfaction barometers and in copious academic studies (Fornell 1992; Johnson, Gustafsson, Andreassen, Lervik, and Cha 2001). The items were formulated as follows in our case: 'How satisfied or dissatisfied are you with this store?' $(1=$ very dissatisfied, $10=$ very satisfied), 'To what extent does this store meet your expectations?' $(1=$ not at all, $10=$ totally), and 'Imagine a store that is perfect in every respect. How near or far from this ideal do you find this store?' ( 1 = very far from, 10 = cannot get any closer). Cronbach's alpha for 
this scale was .94 , and we used the average response to the three items as a satisfaction measure. As a validity check, we included single-item measures of (a) the intention to return to the store and (b) the intention to engage in word-of-mouth regarding the store. Both items were scored on a 10-point scale, and both were significantly and positively associated with customer satisfaction $(r=.83, p<.01 ; r=.86, p<.01)$. The satisfaction measure thus behaved as expected in relation to many previous studies resulting in similar associations.

As a manipulation check, and in the final part of the questionnaire, the participants were given the statement 'The employee was using humor in the conversation with me' to be scored on a scale ranging from 1 (do not agree at all) to 10 (agree completely). A similar check item was used by, for example, Cantor and Venus (1980).

\section{Analysis and results}

To assess the manipulation, we employed a one-way ANOVA on the responses to the manipulation check item (i.e., 'The employee was using humor in the conversation with me'). The omnibus test suggested that all means were not equal $(F=16.06, p<.01)$. The no joke condition $(M=4.90)$ resulted in a lower score than both the offer-related joke condition $(M=$ $7.96)$ and the condition with jokes unrelated to the offer $(M=7.54)$; both differences were significant $(p<.01)$. The manipulation thus behaved as expected.

The mean level of perceived relevance was 8.03 in the no jokes condition, 6.22 in the condition with jokes related to the offer, and 5.88 in the condition with jokes unrelated to the offer. The omnibus test from a one-way ANOVA with a three-level joke factor (no jokes, jokes related to the offer, and jokes unrelated to the offer) showed that all means were not equal $(F=12.71, p<.01)$. Post hoc tests (we used the Scheffé test) showed that no jokes created a significantly higher level of perceived relevance than both jokes related to the offer $(p<.01)$ and jokes unrelated to the offer $(p<.01)$. H1 was thus supported. The two jokes conditions, however, did not produce significantly different levels of perceived relevance $(p=$ .75). $\mathrm{H} 2$ must therefore be rejected.

Customer satisfaction reached a higher level in the no jokes condition $(M=7.91)$ compared to both the condition involving jokes related to the offer $(M=6.26)$ and the condition with jokes unrelated to the offer $(M=6.37)$.The omnibus test from an ANOVA showed that all means 
were not equal $(F=7.74, p<.01)$. Post-hoc tests (again, we used the Scheffé test) showed that the no jokes condition produced a significantly higher level of satisfaction than both the offer-related jokes condition $(p<.01)$ and the condition with jokes unrelated to the offer $(p<$ $.01)$. H3 was thus supported. However, the satisfaction difference between the two jokes conditions was not significant $(p=.97)$, meaning that $\mathrm{H} 4$ was rejected.

Our conceptual reasoning implies that the association between the employee's use of jokes and customer satisfaction is mediated by perceived relevance. To assess this, we used mediation analysis with the Preacher and Hayes bootstrapping approach (Zhao, Lynch, and Chen 2010). In our analysis, the independent variable was employee use of jokes (scored as 1 if there was no jokes and 2 if jokes were used; we aggregated the two jokes groups, because the two joke types did not impact other variables differently). The mediating variable was perceived relevance, and the dependent variable was customer satisfaction. The zero-order correlations between the variables were as follows: $r=-.46(p<.01)$ for the employee use of jokes-perceived relevance association, $r=.73(p<.01)$ for the relevance-satisfaction association, and $r=-.37(p<.01)$ for the use of jokes-satisfaction association. A mediation assessment with Hayes' Model 4 indicated a significant indirect effect from the bootstrap analysis of -1.38 (5000 bootstrap samples, 95\% CI limits -2.04 and -0.84). The direct effect, 0.18 , was not significant $(p=.59)$. This thus suggests that the (negative) effect of employee use of jokes on customer satisfaction was mediated by perceived relevance.

\section{Discussion}

Study 1 showed that employee use of no jokes produced higher levels of (a) perceived relevance and (b) customer satisfaction compared to employee use of jokes. Perceived relevance mediated the use of jokes-customer satisfaction link. The expected differences between jokes related to the offer and jokes unrelated to the offer, however, did not materialize. That is to say, regardless of the type of jokes the employee used, perceived relevance and satisfaction were reduced to the same extent.

However, several studies, theories, and arguments suggest that emotional aspects are likely to be involved in responses to humor (Spotts et al. 1997). Indeed, a common assumption is that humor produces positive affect (Cantor and Venus 1980; Lee and Mason 1999; Martin, 2001; Moran and Massam 1999). And positive affect has an impact on several variables, such as 
elaboration, interpretation, problem solving, and evaluations (van Dolen et al. 2008; Forgas 1995; Forgas and George 2001). For example, the positive affect generated by an ad has been shown to enhance the evaluations of the ad (Muehling and McCann 1993). It therefore seems likely that employee use of jokes would have an impact on the customer's emotional reactions, which in subsequent steps may influence both perceived relevance and customer satisfaction. Yet our Study 1 did not contain any explicit measures of emotions as reactions to what the employee said to the customers. This is indeed a limitation. Therefore, to examine the potential role of emotions, we conducted two additional studies. Study 2 was an attempt to address the emotion issue in physiological terms, while Study 3 employed a setting similar to Study 1, but with explicit measures of emotions included.

\section{Study 2}

A between-subjects experiment was conducted to assess the impact of employee use of jokes on emotions. As in Study 1, the experimental design comprised a joke factor with three levels: (1) no jokes, (2) a joke unrelated to the offer, and (3) a joke related to the offer. We used shorter versions of the Study 1 role-play scenarios, because in Study 2 the scenario text was read to the participants - to obtain a closer correspondence to an actual conversation - and pretesting of the reading activity revealed that there is a limit to how long a text can be when participants listen to it as opposed to reading it. Moreover, in Study 2 the participants' faces were recorded on video while they were exposed to the manipulations. These videos generated facial expression-based data for an assessment of emotional reactions.

\section{Stimulus development}

Shorter versions of each of the Study 1 scenarios were created; in Study 2, the joke manipulations contained only one joke (see Appendix 2). Again, then, the specific form of humor used in the manipulations was joke-telling embedded in a conversation (Boxer and Cortés-Conde 1997; Norrick 2003). Although the joke's share of the overall conversation input from the employee increased in relation to Study 1, the messages in Study 2 should still be seen as 'message dominant' rather than 'humor dominant', in the sense that removals of the jokes would not change the message (Spotts et al. 1997). 


\section{Participants and data collection}

The participants ( $n=30,14$ men and 16 women) were employees at business schools and participants in business administration courses, and they were randomly allocated to one of three scenario versions. The data collection procedure, employed individually for each participant, was as follows: the participants were instructed to look at a sign saying 'It is a very sunny summer day and you are in an eyeglass store to purchase sunglasses' (to keep their heads fixed for the video recording) while one of the three scenario texts in Appendix 2 was read aloud by a researcher. During the reading of the text, a GoPro camera was used to film the participants' faces. This resulted in 30 videos with an average length of about 1.30 minutes. In addition, after the text had been read, the camera was switched off and some questions were asked to the participants.

\section{Measures}

We used FaceReader 6 to capture the participants' emotional reactions to the scenarios. FaceReader 6 is a software that uses facial expressions, as captured by still images or videos, to calculate the level of six basic emotions (happy, sad, surprised, scared, angry, and disgusted) as well as a neutrality. It uses face models synthesized from facial emotional behavior prototypes, and its results have been shown to be subject to high convergent validity with ratings made by human judges (Chentsova-Dutton and Tsai 2010). FaceReader has been used to capture emotions in previous research by, for example, Danner, Sidorkina, Joechl, and Duerrschmid (2013) and de Wijk, Kooijman, Verhoeven, Holthuysen, and de Graaf (2012). A main assumption is that the individual's facial expressions provide useful indications of the individual's emotions (Xiao, Kim, and Ding 2013). The level of the seven emotion variables (range 0-1; the higher the value, the higher the emotional intensity) are computed 30 times per second. In the present study, and for each of the seven emotion variables, we used the average of all observations with respect to the total exposure time in relation to the scenarios as emotion intensity measures. The FaceReader-generated data in our case thus consists of seven observations for each participant, and these observations should be seen as a summary of each participant's emotional state immediately after exposure to the full scenario.

In addition, after exposure to the scenario (and after the camera had been switched off), we asked each participant about the perceived humor content in the scenario. We used the 
statement 'The sales person used humor in the conversation with you', scored on a scale ranging from 1 (do not agree at all) to 10 (agree completely). We also asked the participants about their level of happiness with the question 'How happy do you feel right now?'. It was scored on a scale ranging from 1 (not happy at all) to 10 (very happy).

\section{Analysis and results}

For the manipulation check, we used the humor item ('The sales person used humor in the conversation with you'). Perceived humor content was lower in the no joke condition $(M=$ 3.45) compared to both the offer-related joke condition $(M=7.55)$ and the condition with an offer-unrelated joke $(M=6.50)$. The omnibus test from a one-way ANOVA showed that all means were not equal $(F=13.71, p<.01)$. The perceived humor level in the no joke condition was significantly lower than in the related joke condition $(p<.01)$ and the unrelated joke condition $(p<.01)$. There was no significant difference between the two joke conditions $(p=.47)$. The manipulations thus behaved as expected.

In the next step, we examined the average level of the seven emotional variables generated by FaceReader for the three groups. No significant differences, however, were found. For example, the happiness level was 0.17 for the no joke condition, 0.13 for the offer-related joke condition, and 0.18 for offer-unrelated joke condition $(F=0.25, p=.78)$. Similarly, when we examined the groups' responses to the rating scale-based happiness question, the happiness level was 7.00 in the no joke condition, 7.11 in the offer-related joke condition, and 7.20 in the offer-unrelated joke condition $(F=0.05, p=0.95)$. It may be noted that the FaceReader-generated measures of happiness and the rating scale-based happiness measures were positively associated $(r=.44, p<.05)$, thus providing evidence of convergent validity. More importantly, the perceived humor content variable was not significantly associated with any of the FaceReader-generated emotional variables (all $p>.30$ ), and it was not significantly associated with the rating scale-based happiness measure $(p=.20)$. Thus, it must be contended that the employee use of jokes versus no use of joke conditions did not produce different emotional responses among the participants. 


\section{Discussion}

Several researchers have suggested that humor has an affect-inducing potential, particularly with respect to positive affect (Lee and Mason 1999; Moran and Massam 1999), which in turn is likely to have a valence-congruent impact on evaluations (Muehling and McCann 1993). Given our arguments regarding the disturbing potential of humor when it appears as a part of a message (i.e., humor can reduce perceived relevance), then, one would expect that jokes would reduce positive affect. Our findings in Study 2, however, suggest that use of jokes versus no joke did not produce different levels of emotional responses when also the non-joke content of the conversation was allowed to influence participants. It should thus be noted that our findings were obtained in a context in which jokes were embedded in a conversation in such a way (in the joke conditions) that a joke was only one part of a message. In any case, our findings suggest that joke-generated emotions did not contribute to the response pattern obtained in Study 1. To examine this issue further, however, and to assess if the Study 1 results related to the supported hypotheses (i.e., H1 and H3) would be obtained in another empirical setting, a third study was conducted.

Moreover, it should be noted that our independent variable so far - both conceptually and in terms of the manipulations in Study 1 and Study 2 - has been employee use of jokes. The literature on humor in face-to face conversations, however, sometimes contain another employee humor variable, namely if the employee has a 'sense of humor' (Mathies et al. 2016). For example, in one of the few existing studies on the effects of humor in service encounters, Bergeron and Vachon (2008) found that customers' perceptions of financial advisors' sense of humor correlated positively with customer perceived service quality and customer satisfaction. These results, then, are in conflict with our findings regarding employee use of jokes, so an additional purpose of Study 3 was to examine also the role of the employee sense of humor variable.

\section{Study 3}

Study 3 was a between-subjects experiment. Given that Study 1 yielded non-significant results for different types of jokes (i.e., offer-related jokes vs. jokes unrelated to the offer), it was decided to use a design comprising a joke factor with two levels (no jokes vs. jokes). The purpose of Study 3, then, was to (a) test $\mathrm{H} 1$ and $\mathrm{H} 3$ in a different empirical setting, to (b) 
assess the impact of employee joke usage on emotions, and to (c) examine if a conceptualization of humor in terms of also participants' perceptions of employee sense of humor would contribute to a better understanding of the impact of jokes. Again, a text-based roleplay scenario approach was used.

\section{Stimulus development}

The Study 3 scenario comprised a book store setting; the participants were instructed to assume the role of a customer who visited a book store in order to purchase the book The Great Gatsby by F. Scott Fitzgerald as a birthday gift for a friend - a visit involving a conversation with a salesperson about the content of The Great Gatsby. In Study 3, the theme was the book's content (as seen and as described by a salesperson). Two versions of the scenario, one without employee joke use and the other with employee joke use, were created (see Appendix 3). In the no joke condition, there was no joke-telling by the employee; in the jokes condition, the employee told two jokes in such a way that they were embedded in the conversation. Everything else that happened in the scenarios was kept constant.

\section{Participants and data collection}

The participants $\left(n=142 ; 51\right.$ men and 91 women; $\left.M_{\text {age }}=19.42\right)$, which we recruited from participants in business administration courses, were randomly allocated to one of the two scenario versions. After having read the scenario text, they were asked to respond to a set of questionnaire items.

\section{Measures}

Perceived relevance and customer satisfaction were measured in the same way as in Study 1. For perceived relevance, Cronbach's alpha was .87 . To assess the validity of this scale we used a single-item measure of how easy it was to understand the employee; it was scored on a scale ranging from 1 (difficult) to 10 (easy). The response to this item was positively and significantly associated with the response to the relevance scale $(r=.54, p<.01)$. Given the theoretical argument that relevance facilitates understanding of messages (Heckler and Childers 1992), our relevance measure thus behaved in an acceptable way from a nomological validity point of view. For the customer satisfaction scale, Cronbach's alpha was .94. As a 
validity check, and as in Study 1, we included single-item measures of repatronize intent and the intention to engage in word-of-mouth regarding the store (scored on 10-point scales). Both were significantly and positively associated with customer satisfaction $(r=.34, p<.01$, for repatronize intent; $r=.64, p<.01$, for word-of-mouth intentions). The satisfaction measure thus behaved as expected in relation to many previous studies, which have resulted in positive associations between customer satisfaction and intention variables.

In addition, and in contrast to Study 1, Study 3 contained an explicit assessment of positive affect in terms of a three-item measure of pleasantness. It was captured with the question 'How would you describe your feelings after this store visit?', which was followed by three adjective pairs scored on a 10-point scale ('negative emotions-positive emotions', 'sadjoyful', and 'bad mood-good mood'). Cronbach's alpha for this scale was .89. Moreover, to assess the role of employee sense of humor, the participants were asked to assess the salesperson in terms of the adjective pair 'low sense of humor-high sense of humor' on a 10point scale. This item was presented together with filler items related to some other characteristics of the salesperson. It should be noted that this variable refers to customers' perception of an employee, not people's perceptions of their own sense of humor (which is subject to distinct theorization in the literature; cf. Martin 2001). Finally, to assess the manipulation (i.e., no jokes vs. jokes), we used an approach similar to Study 1 and Study 2; in the very end of the questionnaire, the participants were given the statement 'The employee was using humor in the conversation with me' to be scored on a scale ranging from 1 (do not agree at all) to 10 (agree completely).

\section{Analysis and results}

The manipulation check item reached a higher level in the jokes condition $(M=6.77)$ than in the no jokes condition $(M=3.94)$. This difference was significant $(p<.01, t=9.56)$, suggesting that the manipulation behaved as intended.

To test H1, stating that employee use of jokes would reduce perceived relevance, we compared the level of perceived relevance between the two conditions. This analysis showed that the level of perceived relevance was lower in the jokes condition $(M=6.78)$ than in the no jokes condition $(M=8.15)$. This difference was significant $(p<.01, t=5.78)$; H1 was thus supported. With respect to $\mathrm{H} 3$, stating that employee use of jokes would reduce customer 
satisfaction, our analysis showed that customer satisfaction was lower in the jokes condition $(M=6.96)$ than in the no jokes condition $(M=8.19)$. This difference was significant $(p<.01$, $t=6.98)$, which means that $\mathrm{H} 3$ was supported.

An assessment of affective reactions revealed that positive affect was lower in the jokes condition $(M=6.90)$ than in the no jokes condition $(M=7.33)$, thus indicating that employee use of humor reduced positive affect. The affect difference, however, was not significant at the 5 percent level $(t=1.67, p=.10)$. Therefore, it is contended that the absence or presence of joke usage had no main impact on the affective responses.

Moreover, the sense of humor variable reached a similar level in the no humor condition $(M=$ $5.56)$ as in the humor condition $(M=5.81)$; the difference was not significant $(t=0.64, p=$ .52). The zero-order correlation between this variable and the manipulation check item ('The employee was using humor in the conversation with me') was relatively weak ( $r=.29, p<$ $.01)$. Taken together, this suggests that the two humor aspects - joke usage versus sense of humor - tap into different constructs in relation to an employee. Perhaps more important, and in our data, the two aspects were subject to opposing signs with respect to the association with customer satisfaction; the sense of humor-satisfaction association was positive $(r=.24, p<$ .01), which is consonant with the findings in Bergeron and Vachon (2008), while the employee use of jokes-satisfaction association was negative $(r=-.27, p<.01)$.

Finally, given again that our conceptual reasoning implies that the association between the employee's use of jokes and customer satisfaction is mediated by perceived relevance, we examined this aspect also in Study 3 with the Preacher and Hayes bootstrapping approach (Zhao et al. 2010). The independent variable was employee use of jokes (scored as 1 if there was no jokes and 2 if jokes were used), the mediating variable was perceived relevance, and the dependent variable was customer satisfaction. The zero-order correlations between these variables were as follows: $r=-.19(p<.05)$ for the employee use of jokes-perceived relevance association, $r=.74(p<.01)$ for the relevance-satisfaction association and, as already indicated, $r=-.27(p<.01)$ for the employee use of jokes-satisfaction association. A mediation assessment with Hayes' Model 4 indicated a significant indirect effect from the bootstrap analysis of -0.68 (5000 bootstrap samples, 95\% CI limits -1.01 and -0.41 ), thus suggesting that the (negative) effect of employee use of jokes on customer satisfaction was mediated by perceived relevance. The direct effect of employee joke usage on satisfaction (- 
0.55), however, was also significant ( $p<.01)$, thus suggesting, with the terminology of Zhao et al. (2010), that complementary mediation was at hand.

\section{Discussion}

The Study 3 results were in tune with what was obtained in Study 1 and Study 2, in the sense that (a) employee use of jokes reduced both perceived relevance and customer satisfaction in relation to use of no jokes, (b) perceived relevance mediated the use of jokes-satisfaction association, and (c) use of jokes versus no use of jokes did not produce different levels of affect. In addition, Study 3 showed that (d) employee use of jokes (our main independent variable) behaved differently compared to employee sense of humor (i.e., a humor conceptualization sometimes used in previous studies and reviews; cf. Mathies et al. 2016), thus suggesting that further research would benefit from distinguishing actual use of humor (i.e., behavior) from perceived sense of humor (i.e., a personality trait) with respect to employees.

\section{General discussion}

\section{Summary of main results}

Our main finding was that jokes embedded in a conversation reduced customer satisfaction when jokes were used by an employee in face-to-face interactions with customers. This reduction in satisfaction occurred regardless if the jokes were related or unrelated to of the employee's main message. Our results also indicate that use of jokes had a negative impact on perceived relevance, and that perceived relevance mediated the use of jokes-customer satisfaction link. Moreover, this mediation appears to have occurred mainly in cognitive terms, because we found no differences in emotional reactions between the conditions representing employee usage of jokes versus no joke usage.

\section{Contributions}

The literature on service and sales encounters has produced an impressive list of employeerelated characteristics and behaviors with an impact on customer satisfaction, underscoring that the employee indeed is the organization from the customer's point of view (Bitner et al. 
1990). At the same time, several authors have stressed that conversation is a key element of face-to-face interactions between employees and customers (Grewal et al. 2002; Haas and Kenning 2014). Clearly, then, what the employee says to the customer is likely to have an impact on customer satisfaction. Despite the fact that employees have been observed to use humor in conversations with customers (e.g., Gwinner et al. 1998; Price et al. 1995), however, the effects of this practice has received little attention (Mathies et al. 2016). The present findings therefore contribute to the literature on employees' face-to-face interactions with customers by adding the implications of employee use of jokes as an element in the conversation. As far as we know, this has hitherto only been examined in a correlationalbased study by Bergeron and Vachon (2008) in which employee sense of humor was the independent variable, and our finding regarding the presence of a negative joke usagesatisfaction link is the opposite of what they found. Our findings are also at odds with a recent review of the implications of humor use in service settings by Mathies et al. (2016), who suggest that employee humor use is likely to enhance the customer's experience.

The effects of humor, however, have been studied extensively in the advertising literature. And many studies in this field indicate that ads with humor would produce more favorable responses than ads with no humor. In addition, according to organizational behavior studies, humor used between colleagues in the workplace can improve socialization, reduce tension, create rapport, and boost morale (Morkes et al. 1999). Yet mixed and negative results of humor have also been reported, thus suggesting that humor is not universally superior to nonhumor in a communication context (Chattopadhyay and Basu 1990; Mathies et al. 2016; Speck 1991; Oikarinen and Söderlund 2016). As a specific example, Cantor and Venus (1980) found that no humor in a radio ad produced better recall of information conveyed in the ad than the same ad with humor. Our findings, then, contribute to the humor literature by adding evidence that joke usage can have negative effects on the receiver, particularly in terms of perceived relevance as a mediating variable.

As for contributions to the humor literature in a broader sense, it should be noted that such literature often stresses that humor has emotional implications. Typically, it is assumed that humor induces positive affect (Lyttle 2001), which in the next step informs evaluations (such as the attitude towards the ad) in a valence-congruent way (Lee and Mason 1999; Moran and Massam 1999). Our results in Study 2 and Study 3, however, are in conflict with such findings. Presumably, one main reason is that we examined jokes embedded in a conversation 
in which relatively complex information was transmitted - and in this case emotions, as an immediate response to jokes, are likely to be overshadowed by cognitive reactions stemming from other conversation content than jokes per se. Another possible reason is that emotions in humor studies are typically measured with questionnaire items (such as itemized rating scales) similar to those used for other reaction variables, which may create method-related inflation in the correlations between emotions and other variables. Our use of physiological data in Study 2 to capture emotions, however, represents a reduced risk for unwanted correlations due to common methods. Indeed, to the best of our knowledge, our FaceReader-based approach is the first attempt to examine the emotional impact of humor in a marketing setting with data comprising facial expressions.

Moreover, the literature on humor in everyday conversations (cf. Norrick 2009) has dealt with the potential of humor to disrupt conversations (particularly when the receiver does not understand a joke), at least in terms of acknowledging that this potential exists (e.g., Norrick 1994). Studies in this tradition, however, are typically qualitative and rarely test if this or that effect of humor occurs. Our approach in the present study - and our findings - can therefore be seen as a contribution to the discourse on humor usage within the frame of conversations. In addition, it is sometimes claimed that humor in a conversation is a way to free the sender of humorous messages from responsibility of what is said. For instance, it has been argued that humor 'officially does not count'; it can be used to raise issues that would be more or less unacceptable if expressed seriously (Emerson 1969). It may very well be so with respect to the humor part per se, yet our findings show that jokes indeed impact the receivers' view of the overall message.

\section{Managerial implications}

Given many studies showing that humor in ads can have positive effects on customers, and given also that a relatively high share of all ads comprise humor in one way or another, it may be tempting for service and retail managers to consider humor as a component that should be included in employees' interaction with customers. Moreover, some firms appearing as inspiration examples in the service management literature, such as Southwest Airlines, indeed seem to encourage employees' use of humor (Sunoo 1995). It also seems likely that joketelling may be particularly attractive form of humor for managers, because jokes are tangible expression of humor - expressions that can be incorporated in instructions to employees, even 
in the form of specific jokes to be told to customers. Indeed, the use of instructions for employees with such a high level of standardization that they comprise the very jokes to be told has been reported by Leidner (1993). From a customer satisfaction-boosting point of view, and given a setting with relatively rich information exchange, however, our results suggest that retail and service employees involved in conversations with customers should not use humor in the form of joke-telling - neither jokes related to the content of the conversation nor jokes unrelated to this content. Given the positive associations between satisfaction and both intentions to return and intentions to engage in word-of-mouth generated by Study 1 and Study 3 , the results also indicate that joke usage can have negative implications for other customer responses typically considered valuable by managers.

At the same time, however, our findings show that perceived relevance is positively associated with customer satisfaction. Thus perceived relevance is an additional variable that calls for managerial attention, particularly in situations in which the conversation between the employee and the customer involves more than merely greeting the customer and saying 'Thank you'. And usage of jokes can hardly be the only component influencing perceived relevance. In other words, our results have implications beyond the use of jokes: they suggest that managers should be mindful of conversational aspects that affect the overall theme in the employee's communications with customers. The presence of a cohesive theme should be taken seriously; a theme has the potential to differentiate an offer and make the experience easier to remember for the customer (Bryman 1994; Pine and Gilmore 1998). In relation to ads and other communication materials, however, the face-to-face encounter typically exists only in real time; it does not generate a text that can be re-examined later. As a point of departure for managerial assessments of the extent to which employee conversations comprise coherent themes, then, it would be advisable to document what is actually said between the parties in face-to-face encounters in such a way that the content can be analyzed and perhaps also used explicitly in training programs.

\section{Limitations and suggestions for further research}

Humor exists in many different forms (Dynel 2009; Speck 1991), and the present study examined only one form, namely joke-telling. Although some authors consider joke-telling as the prototypical form of verbal humor (Dynel 2009), it has several characteristics that may contribute to making it less-well integrated in a conversation; it is a highly conventionalized 
and socially bound speech behavior (Boxer and Cortés-Conde 1997), and it challenges the listeners to prove their understanding. Indeed, as already indicated, a joke can be seen as 'a little intelligence test' (Norrick 2003). In contrast, conversational joking (wordplay, banter, puns, witticisms, irony, and personal narratives) represents a more playful and interactive joking mode in which humor emerges from the situation itself (Boxer and Cortés-Conde 1997; Dynel 2009; Norrick 1994; Norrick 2003). Such humor may be perceived to be more integrated in a conversation, which may affect perceived relevance (and, in turn, its impact on evaluation variables). Moreover, the ways in which a joke is told (e.g., in terms of tone of voice and facial expression) are likely to affect the impact of the joke (Beermann and Ruch 2009), yet such aspects were held constant in our scenario-based approaches and could therefore not be examined. In addition, the conversations in which jokes appeared in the present study were characterized by the transmission of product-related facts from employees to customers. Other conversation modes, however, may provide a setting in which the impact of joke usage is different. For example, employee joke or humor usage in a storytelling mode can have a positive impact on perceived relevance and on purchase intentions (Gilliam et al. 2014). Further research should therefore examine (a) the impact of other forms of humor than joke-telling, (b) the contribution of how jokes are told, and (c) other conversational modes than the transfer of product facts before the final word is said about joke usage and its potential to influence customer satisfaction.

As for the mechanisms explaining why jokes can have a negative impact on customer satisfaction, we focused on perceived relevance. It should be observed that our notion of perceived relevance was based on the existence of a theme, and that our results were obtained by manipulations for which the idea was that a theme should be present ('differences between cheap and expensive sunglasses' in Study 1 and Study 2; 'the content of The Great Gatsby' in Study 3). All employee-customer conversations, however, may not have a theme, and in no theme-situations the effects of jokes and other types of humor may be different. In any event, other mechanisms than perceived relevance may contribute to satisfaction outcomes. First, one possibility is that employee use of jokes may signal various characteristics of the employee - and such characteristics may in the next step have an impact on customer satisfaction. For example, a person using humor may be perceived as less trustworthy and maybe even as less intelligent (Bressler and Balshine 2006) and - given that trustworthiness and intelligence are positively valued personal characteristics of an employee - such perceptions may have a negative impact on customer satisfaction. Similarly, exposure to a 
person using humor can generate inferences about the person's moral standing (in terms of both vice and virtue; Beerman and Ruch 2009), and such inferences can influence satisfaction assessments. Second, although prior research has documented that employees use humor in conversations with customers (Gwinner et al. 1998; Pearce 2009; Ryoo 2005), the extent of such humor usage is unknown. Assuming that it occurs less frequently in face-to-face encounters than in ads, such usage may represent an atypical situation - and exposure to an atypical employee encourages additional information processing from the customer (Sujan et al. 1986). Presumably, atypicality may have an impact also on customer satisfaction (particularly if it is defined as a function of the customer's expectations). A related issue is that employee use of jokes may be subject to variation with respect to its congruence with other elements in the firm's brand-building activities. For example, joke usage may be natural or even expected when the customer interacts with employees in a firm that communicates 'fun' aspects of its offers and brands. In addition, the receiver's own sense of humor, as a receiver personality trait variable, may affect the impact of humor used by others on various receiver responses (Martin and Lefcourt 1984; Martin 2001). Other receiver personality traits - such as conservatism, tolerance of ambiguity, and sensation-seeking - may indeed contribute to such responses (Ruch et al. 1990; Ruch and Rath 1993). The receiver's mood state may also have an impact (Ruch, Köhler and van Thriel 1997). These, then, are aspects calling for attention in further attempts to come to terms with the effects of employee usage of jokes on customers' reactions.

In addition, the specific face-to-face interactions in the present study may have affected the outcomes. First, the conversations were relatively information-dense, implying a setting with high involvement. Humor, however, is likely to affect evaluations stronger in a low involvement setting (Chung and Zhao 2003; Speck 1991). Further research should therefore examine settings in which the level of involvement is explicitly taken into account (e.g., by contrasting products that are cheap vs. expensive and/or subject to variation in terms of their personal importance for the consumer). Second, in each of our experiments, the interaction between the employee and the salesperson was implicitly depicted as an interaction between two strangers. In more established relations, however, the effects of using jokes may be different. Advertising studies have shown that humorous ads are more effective when customers have prior (and positive) evaluations of the advertised brand (Lee and Mason 1999), and the possibility of such effects needs to be examined by allowing for customeremployee relations with a history prior to the employee using jokes in one particular 
interaction. It may be noted that the positive correlation between customers' perceptions of financial advisors' sense of humor and customer satisfaction reported by Bergeron and Vachon (2008) was obtained in a setting with long-term relations between advisors and clients. Third, again in each experiment in the present study, employee joke usage occurred before customers' purchase decisions. It is possible, however, that customers enter another type of information processing mode once a purchase is completed and thus joke usage after a purchase may have other effects. This aspect clearly merits further research efforts. Thus, the level of involvement, the nature of the employee-customer relationship, and the timing of joke usage within an encounter may represent moderating variables that should be examined in further studies.

Finally, our experimental approach shares a limitations with many other experiments in consumer behavior settings: our study dealt with customer responses obtained immediately after exposure to employee behavior. This means that we did not capture long-term effects of joke usage. It has been claimed, however, that (relevant) humor has a positive impact on recall of the claims made in a message (Krishnan and Chakravarti 2003), and that humorous messages can have a positive 'sleeper' effect (Nabi et al. 2007). If this happens also in a faceto-face setting, the effects of joke usage may not be solely negative. 


\section{Appendix 1: The scenarios for Study 1*}

You will be traveling quite far by car, and when this trip begins you realize that you have forgotten to bring your sunglasses. You immediately feel that this trip will not be comfortable, because the sun is really strong. And you are not very satisfied with the sunglasses you have forgotten, so it's time to buy a new pair anyway. Your company in the car suggests that you could perhaps buy sunglasses at a gasoline station, but you say that you want to buy them in an eyeglass store - and you persuade your company that this is the way it is going to be.

When you enter the eyeglass store a salesperson approaches, greets you, and asks if you need help. You say that you first want to look around on your own. After a while you find some sunglasses that look good on you. They differ quite a lot, however, in terms of the price. You have to think carefully about what to choose. The salesperson is approaching again and asks if you need help.

"Would I get better protection with expensive sunglasses compared to cheap sunglasses?", you ask.

"No, there is no such difference for the sunglasses we sell in this store. All of them, regardless of the price, perform at an equal level in terms of UV protection", says the salesperson.

“UV protection?” you ask.

"Well, it is about the amount of ultraviolet light that passes the lenses. And such light is harmful, it may damage the eye's cornea. All of our sunglasses, however, both low-priced and high-priced glasses, have passed the standard level for UV protection. They are marked with CE", says the salesperson and shows the CE marking on the sunglasses you have tried on.

"Hmm...is there any difference between cheap and expensive sunglasses when it comes to how they perform?" you ask.

\section{"Do you know what Tarzan said when he saw that the elephants coming over the hill were wearing expensive sunglasses?" asks the salesperson.}

"No?" you say.

"Nothing, because he did not recognize them! You should of course consider the refraction factor: the lower the level of optical refraction error, the better it is. But the refraction error variation between our cheap and expensive sunglasses is more or less zero. And you should pay attention to how sensitive they are for scratches. For this aspect, there are indeed differences between low-priced and high-priced sunglasses. Those that are more expensive, with mineral glass lenses, are basically 100 percent resistant to scratches. The cheaper ones, however, will get scratches - especially if you wipe them with your shirt. Polaroid lenses are also good if you do not want scratches. They have a different surface, which makes it hard for dirt to get stuck", says the salesperson.

"Right now I need sunglasses to wear in a car, I do not think they will become very dirty in there", you say. 
"OK, if you are driving, I would really recommend Polaroid lenses. They are superior when there is strong light. There are actually tests showing that drivers wearing Polaroid lenses in strong light conditions stop faster when confronted with various obstacles. The letter "P" or the word "Polarized" on one of the lenses show if the glass is polarized", says the salesperson.

"Well, then I think I would want to have this pair of sunglasses" you say and you show the salesperson one of the pairs that you have tried on.

"Wait, try them on, so I can see how they fit", says the salesperson.

You put the sunglasses on. The salesperson looks at you for a while.

"Do you know why you should wear sunglasses when you propose to someone that you should get married?" asks the salesperson.

"No", you say.

"So that you do not get blinded by the beauty of the potential partner! You look good with these! You have to take the appeal factor into account when you select sunglasses", says the salesperson.

"Fine, I would like to have them", you say. You pay, you thank the salesperson, and you walk towards the car. It is indeed very sunny today, so you put on your new sunglasses immediately. Now you are ready for the road.

*The parts in bold was used for the condition with offer-related humor. This part was absent in the no humor condition. For the condition with offer-unrelated humor, these part were used:

"It's hot today, right? Have you heard the story about the fortune tellers?" asks the salesperson.

“No?” you say.

"The first one said that it was going to be a hot summer. Then the second said: 'Yes, it reminds me of the summer 2092'.

"Do you know why the elephant was wearing green socks?" asks the salesperson.

"No", you say.

"Because his red socks were wet!", says the salesperson. 


\section{Appendix 2: The scenarios for Study 2*}

It is a very hot and sunny day and you feel the need for sunglasses. You go to an eyeglasses store to purchase sunglasses and in this store you interact with a salesperson. Here is what happens in the interaction:

"Would I get better protection with expensive sunglasses compared to cheap sunglasses?", you ask.

"No, there is no such difference for the sunglasses we sell in this store. All of them, regardless of the price, perform at an equal level in terms of UV protection", says the salesperson.

“UV protection?” you ask.

"Well, it is about the amount of ultraviolet light that passes the lenses. And such light is harmful, it may damage the eye's cornea. All of our sunglasses, however, both low-priced and high-priced glasses, have passed the standard level for UV protection. They are marked with CE", says the salesperson and shows the CE marking on the sunglasses you have tried on.

"Hmm...is there any difference between cheap and expensive sunglasses when it comes to how they perform?" you ask.

"Do you know what Tarzan said when he saw that the elephants coming over the hill were wearing expensive sunglasses?" asks the salesperson.

“No?" you say.

"Nothing, because he did not recognize them! You should of course consider the refraction factor: the lower the level of optical refraction error, the better it is. But the refraction error variation between our cheap and expensive sunglasses is more or less zero. And you should pay attention to how sensitive they are for scratches. For this aspect, there are indeed differences between low-priced and high-priced sunglasses. Those that are more expensive, with mineral glass lenses, are basically 100 percent resistant to scratches. The cheaper ones, however, will get scratches - especially if you wipe them with your shirt.

*The part in bold was used for the condition with offer-related humor. This part was absent in the no humor condition. For the condition with offer-unrelated humor, this part was used:

"It's hot today, right? Have you heard the story about the fortune tellers?" asks the salesperson.

“No?” you say.

"The first one said that it was going to be a hot summer. Then the second said: 'Yes, it reminds me of the summer 2092'. 
Appendix 3: The scenarios for Study 3*

One of your friends will soon have a birthday and you need a gift. You have decided that you would like to give a book - and that this book should be a real classic. After thinking about this for a while you feel that The Great Gatsby by F. Scott Fitzgerald may be an option. You go to a bookstore and locate the department for classics and there you find The Great Gatsby. You pick up one copy and examine it. A salesperson approaches.

“Hi, do you need any help?” asks the salesperson.

You explain that you are looking for a gift for a friend's birthday and that you are considering this particular book. And you say that you want your gift to be memorable.

"I can almost promise that this book will be a memorable gift!" says the salesperson.

"Why is that?" you ask.

"This is a real classic", says the salesperson.

"Hmm...what do you mean when you say that it is a classic?" you ask.

"A classic is a book that is discovered by new generations of readers; it's a book that stays alive for a very long period", says the salesperson.

"It seems a bit old, I want to give it to a person in my own age, would that really work?" you ask.

"Well, it was published during the 1920s. Somehow it is a portrait of the 1920s, but it comprises several timeless themes", says the salesperson.

"In more concrete terms, what would you say that this book is about?" you ask.

"The main character, Gatsby, is a mysterious millionaire - known among other things for his extravagant parties - who has had a relationship with a girl that left him and married another man. But Gatsby is still in love with her and we wants her back. He is indeed successful in making this happen, but her husband discovers their relationship. He becomes extremely upset, and the result is a conflict between several parties. Among other things, it is revealed that Gatsby created his wealth by means that are not exactly legal. It is indeed possible to argue that the book problematizes the relation between wealth and love. By the way, have you heard about the sad man in the bar?" asks the salesperson.

"No", you say.

"Well, a man who looked sad was sitting in bar. The bartender asked why he was sad. 'My wife has made me a millionaire', says the man. 'If my wife made me a millionaire, I would certainly by happy', says the bartender. "But before I met her I was a billionaire', says the man."

"Hmm...how does the story about Gatsby end?", you ask. 
"The book was supposed to be a gift, right? But you may want to read it yourself, so I should not tell you how it ends", says the salesperson.

"Come on, tell me how it ends", you say.

"One of the characters dies, Gatsby is blamed for this, and he is killed by another character", says the salesperson.

“This does not seem very encouraging”, you say.

"This is not a detective story, the killing is only a tiny part of the story. In fact, many think that this is The Great American Novel, in the sense that it depicts the kaleidoscope of the nation, its social fabric and its troubled conscience. There are several universal themes in the book - such as the wish to be able start all over again, the difficulties with ideals, the way in which social demands can become restrictions, and how modernity changes the status of privileged classes. Of course it is also about the difficulties with love and relationships and the problems with expectations that are not met. By the way, have you heard about the two mobile telephones? Well, they fell in love, and they decided that they should get married. The ceremony in the church, however, became a disaster, because no guests came. But the reception afterwards was really good! Anyway, some people think that the death of Gatsby was really the end of The American Dream. In any event, one could say that The Great Gatsby is a book about betrayal and impossible love. And these are indeed timeless themes. To read this book is to look into a mirror - we see ourselves and the time in which we live right now, I promise. So you do not need to worry that the story would be perceived as old", says the salesperson.

You say that you want to read back cover text and that you need some time to think about buying this book.

"Sure! Just let me know if you want more information. We also have another book by Fitzgerald, The Beautiful and Damned. This book deals with the difficulties in having relationships, too. And of course we have many other classics", says the salesperson and goes to another part of the store.

*The parts in bold was used for the condition with employee humor usage. 


\section{References}

Alden, D.L. and Hoyer, W.D. (1993), An examination of cognitive factors related to humorousness in television advertising, Journal of Advertising, 22 (2), 29-37.

Alden, D.L., Hoyer, W.D. and Lee, C. (1993), Identifying global and culture-specific dimensions of humor in advertising: A multinational analysis, Journal of Marketing, 57 (2), 64-75.

Ang, S.H., Lee, Y.H. and Leong, S.M. (2007), The ad creativity cube: Conceptualization and initial validation, Journal of the Academy of Marketing Science, 35 (2), 220-232.

Bergeron, J. and Vachon, M.-A. (2008), The effects of humour usage by financial advisors in sales encounters, The International Journal of Bank Marketing, 26 (6), 376-398.

Bitner, M.J. (1990), Evaluating service encounters: The effects of physical surroundings and employee responses, Journal of Marketing, 54 (April), 69-82.

Bitner, M.J., Booms, B.H. and Tetreault, M.S. (1990), The service encounter: Diagnosing favorable and unfavorable incidents. Journal of Marketing, 54 (January), 71-84.

Boxer, D. and Cortés-Condes, F. (1997), From bonding to biting: Conversational joking and identity display, Journal of Pragmatics, 27 (3), 275-294.

Bressler, E.R and Balshine, S. (2006), The influence of humor on desirability, Evolution and Human Behavior, 27 (1), 29-39.

Bryman, A. (1994), The Disneyization of Society, London: SAGE.

Calder, B.J., Phillips, L.W. and Tybout, A. M. (1981), Designing research for application, Journal of Consumer Research, 8 (2), 197-207.

Cantor, J. and Venus, P. (1980), The effect of humor on recall of a radio advertisement, Journal of Broadcasting, 24 (1), 13-22.

Chattopadhyay, A. and Basu, K. (1990), Humor in advertising: The moderating role of prior brand evaluation, Journal of Marketing Research, 27 (4), 466-476.

Chentsova-Dutton, Y.E. and Tsai, J.L. (2010), Self-focused attention and emotional reactivity: The role of culture, Journal of Personality and Social Psychology, 98 (3), 507-519.

Chung, H. and Zhao, X. (2003), Humor effect on memory and attitude: Moderating role of product involvement, International Journal of Advertising, 22 (1), 117-144.

Cowan, M.L. and Little, A.C. (2013), The effects of relationship context and modality on ratings of funniness, Personality and Individual Differences, 54 (4), 496-500.

Danner, L. Sidorkina, L., Joechl, M. and Duerrschmid, K. (2013), Make a face! Implicit and explicit measurement of facial expressions elicited by orange juices using face reading technology, Food Quality and Preference, 32 (March), 167-172. 
De Keyzer, F., Dens, N. and De Pelsmacker, P. (2015), Is this for me? How consumers respond to personalized advertising on social network sites, Journal of Interactive Advertising, 15 (2), 124-134.

van Dolen, W.M., de Ruyter, K. and Streukens, S. (2008), The effect of humor in electronic service encounters, Journal of Economic Psychology, 29 (2), 160-179.

Dunbar, R.I.M., Launay, J., and Curry, O. (2016). The complexity of jokes is limited by cognitive constraints on mentalizing. Human Nature, 27 (2), 130-140.

Duncan, C.P. (1979). Humor in advertising: A behavioral perspective, Journal of the Academy of Marketing Science, 7 (4), 285-306.

Dynel, M. (2009), Beyond a joke: Types of conversational humor, Language and Linguistics Compass, 3 (5), 1284-1299.

Eisend, M. (2009), A meta-analysis of humor in advertising, Academy of Marketing Science Journal, 37 (2), 191-203.

Emerson, J.P. (1969), Negotiating the serious import of humor, Sociometry, 32 (2), 169-181.

Erevelles, S. (1998), The role of affect in marketing, Journal of Business Research, 42 (3), 199-215.

Fornell, C. (1992), A national satisfaction barometer: The Swedish experience, Journal of Marketing, 56 (January), 6-21.

Forgas, J.P. (1995), Mood and judgment: The affect infusion model (AIM), Psychological Bulletin, 117 (1), 39-66.

Forgas, J.P. and George, J.M. (2001), Affective influences on judgments and behavior in organizations: An information processing perspective, Organizational Behavior and Human Decision Processes, 86 (1), 3-34.

Fugate, D.L. (1998), The advertising of services: What is an appropriate role for humor, The Journal of Services Marketing, 12 (6), 453-472.

Gilliam, D.A., Flaherty, K.E. and Rayburn, S.W. (2014), The dimensions of storytelling by retail salespeople, The International Review of Retail, Distribution and Consumer Research, 24 (2), 231-241.

Graham, E.E., Papa, M.J. and Brooks, G.P. (1992), Functions of humor in conversation: Conceptualization and measurement, Western Journal of Communication, 56 (Spring), 161183.

Grewal, D., Levy, M. and Marshall, G.W. (2002), Personal selling in retail settings: How does the Internet and related technologies enable and limit successful selling?, Journal of Marketing Management, 18 (3-4), 301-316. 
Gwinner, K.P., Gremler, D.D. and Bitner, M.J. (1998), Relational benefits in services industries: The customer's perspective, Journal of the Academy of Marketing Science, 26 (2), $101-114$

Haas, A. and Kenning, P. (2014), Utilitarian and hedonic motivators of shoppers' decision to consult with salespeople, Journal of Retailing, 90 (3), 428-441.

Hay, J. (2000), Functions of humor in the conversations of men and women, Journal of Pragmatics, 32 (6), 709-742.

Heckler, S.E. and Childers, T-L. (1992), The role of expectancy and relevancy in memory for verbal and visual information: What is incongruency?, Journal of Consumer Research, 18 (March), 475-492.

Houston, M.J., Childers, T-L. and Heckler, S.E. (1987), Picture-word consistency and the elaborative processing of advertisements, Journal of Marketing Research, 24 (November), 259-369.

Johnson, M.D., Gustafsson, A., Andreassen, T.W., Lervik, L. and Cha, J. (2001), The evolution and future of national satisfaction index models, Journal of Economic Psychology, $22(2), 217-245$.

Karande, K., Magnini, V.P. and Tam, L. (2007), Recovery voice and satisfaction after service failure: An experimental investigation of mediating and moderating factors, Journal of Service Research, 10 (2), 187-203.

Katz, D. (1972), Some final considerations about experimentation in social psychology. In: McClintock, C.C. (Ed.), Experimental social psychology, 549-561, New York: Holt, Reinhart and Winston.

Krishnan, H.S. and Chakravarti, D. (2003), A process analysis of the effects of humorous advertising executions on brand claims memory, Journal of Consumer Psychology, 13 (3), 230-245.

Lee, Y.H. and Mason, C. (1999), Responses to information incongruency in advertising: The role of expectancy, relevancy, and humor, Journal of Consumer Research, 26 (September), 156-169.

Leidner, R. (1993), Fast food, fast talk: Service work and the routinization of everyday life, Berkeley: University of California Press.

Locke, K. (1996), A funny thing happened! The management of consumer emotions in service encounters, Organizational Science, 7 (1), 40-59.

Luo, X. and Homberg, C. (2007), Neglected outcomes of customer satisfaction, Journal of Marketing, 71 (2), 133-149.

Lyttle, J. (2001), The effectiveness of humor in persuasion: The case of business ethics training, The Journal of General Psychology, 128 (2), 206-216. 
Madden, T.J. and Weinberger, M.G. (1984), Humor in advertising: A practitioner view, Journal of Advertising Research, 24 (4), 23-29.

Martin, R.A. and Lefcourt, H.M. (1983), Sense of humor as a moderator of the relation between stressors and moods, Journal of Personality and Social Psychology, 45 (6), 1313 1324.

Martin, R.A. (2001), Humor, laughter, and physical health: Methodological issues and research findings. Psychological Bulletin, 127(4), 504-519.

Martin, R.A., Puhlik-Doris, P., Larsen, G., Gray, J. and Weir, K. (2003), Individual differences in uses of humor and their relation to psychological well-being: Development of the Humor Styles Questionnaire, Journal of Research in Personality, 37 (1), 48-75.

Mathies, C., Chiew, T.M. and Kleinaltenkamp, M. (2016), The antecedents and consequences of humor for services, Journal of Service Theory and Practice, 26 (2), 137-162.

Moran, C.C. and Massam, M.M. (1999), Differential influences of coping humor and humor bias on mood, Behavioral Medicine, 25 (Spring), 36-42.

Morkes, J., Kernal, H.K. and Nass, C. (1999), Effects of humor in task-oriented humancomputer interaction and computer-mediated communication: A direct test of SRCT theory, Human-Computer Interaction, 14 (4), 395-435.

Muehling, D.D. and McCann, M. (1993), Attitude toward the ad: A review, Journal of Current Issues and Research in Advertising, 15 (2), 25-58

van Mulken, M. van Enschot, R. and Hoeken, H. (2005), Levels of implicitness in magazine advertisements, Information Design Journal + Document Design, 13 (2), 155-164.

Nabi, R-L., Moyer-Gusé, E. and Byrne, S. (2007), All joking aside: A serious investigation into the persuasive effect of funny social issue messages, Communication Monographs, 74 (1), 29-54.

Norrick, N.R. (1994), Involvement and joking in conversation, Journal of Pragmatics, 22 (34), 409-430.

Norrick, N.R. (2003), Issues in conversational joking, Journal of Pragmatics, 35 (9), 1333 1359.

Norrick, N.R. (2009), A theory of humor in interaction, Journal of Literary Theory, 3 (2), 261-283.

Oikarinen, E.L. and Söderlund, M. (2016). The effects of humour in online recruitment advertising. Australasian Marketing Journal, 24 (3), 180-186.

Pearce, P.L. (2009), Now that is funny: Humour in tourism settings, Annals of Tourism Research, 30 (4), 627-644.

Phillips, B.J. (2000), The impact of verbal anchoring on consumer response to image ads, Journal of Advertising, 24 (1), 15-24. 
Pine, B.J. and Gilmore, J.H. (1998), Welcome to the experience economy, Harvard Business Review, 76 (4) 97-105.

Price, L.L., Arnould, E.J. and Tierney, P. (1995), Going to extremes: Managing service encounters and assessing provider performance, Journal of Marketing, 59 (April), 83-97.

Reber, R., Winkielman, P. and Schwarz, N. (1998), Effects of perceptual fluency on affective judgments, Psychological Science, 9 (1), 45-48.

Robinson, D.T. and Smith-Lovin, L. (2001), Getting a laugh: Gender, status, and humor in task discussions, Social Forces, 80 (1), 123-158.

Ruch, W., McGhee, P.E. and Hehl, F.J. (1990), Age differences in the enjoyment of incongruity-resolution and nonsense humor during adulthood, Psychology and Aging, 5 (3), 348-355.

Ruch, W. and Rath, S. (1993), The nature of humor appreciation: Toward an integration of perception of stimulus properties and affective experience, Humor, 6 (4), 363-363.

Ruch, W., Köhler, G. and van Thriel, C. (1997), To be in good or bad humour: Construction of the state form of the State-Trait-Cheerfulness-Inventory-STCI, Personality and Individual Differences, 22 (4), 477-491.

Beermann, U. and Ruch, W. (2009), How virtuous is humor? What we can learn from current instruments, The Journal of Positive Psychology, 4 (6), 528-539.

Ryoo, H.-K. (2005), Achieving friendly interactions: A study of service encounters between Korean shopkeepers and African-American customers, Discourse and Society, 16 (1), 79-105.

Scott, C. Klein, D.M. and Bryant, J. (1990), Consumer response to humor in advertising: A series of field studies using behavioral observation, Journal of Consumer Research, 16 (March), 498-501.

Smith, R.E., Chen, J. and Yang, X. (2008), The impact of advertising creativity on the hierarchy of effects, Journal of Advertising, 37 (4), 47-61.

Speck, P.S. (1991), The humorous message taxonomy: A framework for the study of humorous ads, Current Issues and Research in Advertising, 13 (1-2), 1-44.

Spotts, H.E, Weinberger, M.G. and Parsons, A.L. (1997), Assessing the use of and impact of humor on advertising effectiveness: A contingency approach, Journal of Advertising, 24 (3), $17-32$.

Sternhal, B. and Craig, C.S. (1973), Humor in advertising, Journal of Marketing, 37(4), 1218 .

Sujan, M., Bettman, J.R. and Sujan, H. (1986), Effects of consumer expectations on information processing in selling encounters, Journal of Marketing Research, 23 (November), 346-353. 
Sunoo, B.P. (1995), How fun flies at Southwest Airlines, Personnel Journal, 74 (6), 62-71.

Surprenant, C.F. and Solomon, M.R. (1987), Predictability and personalization in the service encounter, Journal of Marketing, 51 (April), 73-80.

Söderlund, M. and Rosengren, S. (2008), Revisiting the smiling service worker and customer satisfaction, International Journal of Service Industry Management, 19 (5), 552-574.

Webster, C. and Sundaram, D. S. (2009), Effect of service provider's communication style on customer satisfaction in professional services setting: The moderating role of criticality and service nature. Journal of Services Marketing, 23 (2), 103-113.

Weinberger, M.G. and Gulas, C.S. (1992), The impact of humor in advertising: A review, Journal of Advertising, 21 (9), 35-59.

Weinberger, M.G. and Spotts, H.E. (1989), Humor in U.S. versus U.K. TV commercials: A comparison, Journal of Advertising, 18 (2), 39-44.

de Wijk, R.A., Kooijman, V., Verhoeven, R.H.G., Holthuysen, N.T.E. and de Graaf, C. (2012), Autonomic nervous system responses on and facial expressions to the sight, smell, and taste of liked and disliked foods, Food Quality and Preference, 26 (2), 196-203.

Xiao, L., Kim, H.-J. and Ding, M. (2013), An introduction to audio and visual research and applications in marketing, Review of Marketing Research, 10, 213-253.

Zhao, X., Lynch, J.G. and Chen, Q. (2010), Reconsidering Baron and Kenny: Myths and truths about mediation analysis, Journal of Consumer Research, 37 (August), 197-206. 